\title{
'Spoken Drama (Huaju) with a Strong Chinese Flavour': The Resurrection and Demise of Popular Spoken Drama (Tongsu Huaju) in Shanghai in the 1950 and Early 1960 s
}

\author{
SIYUAN LI U
}

In the late 1950 s and early 1960 in Shanghai, the remnant of wenmingxi (civilized drama), China's first form of Western-style spoken drama, which had flourished in the 190os and 1910s as a hybrid of Western spoken theatre and indigenous performance, experienced a brief resurrection and ultimate demise under the name of tongsu huaju (popular spoken drama). Considered until then as popular entertainment inferior to the officially recognized form of modern theatre, huaju (spoken drama), that adhered to Western realistic dramaturgy and performance, tongsu huaju staged a six-play festival in January 1957 thanks to liberal art policies, received a warm welcome in Beijing and other cities, and attracted the attention of some huaju experts who praised its affinity to indigenous performance, thus triggering a debate over its efficacy as a localized alternative to huaju for the future of modern Chinese theatre. Using contemporary sources, this article examines tongsu huaju's brief rise and fall in Shanghai, with a focus on its performances, the debate, the policy changes that decided the fate of China's first form of modern theatre, and the implications of its fate for the narrative of periodization in modern Asian theatre.

The history of modern, Western-style spoken theatre in Asia since the late nineteenth century can generally be divided into four relatively distinct periods: (1) an initial hybridization of indigenous and Western traditions, (2) an orthodox adherence to Western realism, (3) the rediscovery of national culture and (4) contemporary globalism. ${ }^{1}$ In the case of China, these four periods generally correspond to (1) wenmingxi (civilized drama) of the 1900 and 1910s, which flourished in Shanghai as a hybrid of Western spoken theatre, indigenous Chinese theatre, and Japan's first form of modern theatre, shinpa (new-school drama), itself a hybrid of spoken drama and kabuki; (2) huaju (spoken drama), which started in the early 1920 s as antidote to wenmingxis hybridities and as a socially conscious, script-centric and speech-only theatre based on Western realism and inspired by the anti-traditional zeitgeist of the late 1910s New Cultural Movement; (3) experimental theatre of the 1980 os and 1990s that blended Western modernist theatre and indigenous Chinese dramaturgy and theatricality as a reaction to orthodox huaju; and (4) globalized spoken theatre of the new millennium. ${ }^{2}$

However, while these general and homogenizing trends are largely true, what is equally important is to recognize the cross-currents within each period, particularly 
during the second phase of westernizing, realistic orthodoxy that dominated much of the twentieth century and blocked various attempts to hybridize spoken drama with indigenous dramaturgy and performance. Identifying these countercurrents and the sociopolitical, cultural and theatrical dynamics that determined centre-periphery relations and the ultimate fate of these undercurrents will significantly complicate existing narratives of theatrical modernity in Asia. As I have discussed elsewhere, one example of this centre-periphery dynamic is China's failed national theatre movement (guoju yundong) of 1925-6, at the beginning of the huaju phase, when a group of recently returned Western-educated intellectuals introduced contemporary European theatrical anti-realism, including its admiration for Asian theatre, and advocated infusing huaju with traditional Chinese theatre's formal conventions in staging and performance. ${ }^{3}$ Yet while their advocacy was much closer to the dominant trend of Western theatre of the time, they were relentlessly attacked as capitulating to the decadent feudal theatre and quickly defeated by their students and other practitioners, who had never been abroad. In other words, the anti-traditional wave of the era allowed the movement's opponents, with supposedly inferior academic and social status, to declare victory over the advocates with up-to-date knowledge of Western theatre. What this encounter tells us, then, is that even this supposedly most 'Western' phase of modern Asian theatre was at least as much a product of domestic political, social and cultural conditions as it was a reflection of concurrent Euro-American theatre, if not more so.

In this article, I will examine another ultimately futile attempt to bring indigenous Chinese theatricality to huaju. It occurred closer to the end of the orthodoxy phase, in 1957 and a few years afterwards, when the remnants of the hybrid wenmingxi-known by that time as tongsu huaju (popular spoken drama) - caused brief excitement among some theatre experts who had been frustrated by the stereotypical characters and lacklustre performances they had witnessed in the previous year's national huaju festival. As it happened, 1957 corresponded to a brief period of liberal art policies in China, in part resulting from Nikita Khrushchev's 1956 'Secret Speech' against Josef Stalin that sparked policy thaws in the Soviet Union and elsewhere in the socialist world. Specifically, the liberal policy allowed the performance of previously censored traditional plays, including the hybrid tongsu huaju. Accordingly, a festival was held in Shanghai to demonstrate the genre's uniquely 'Chinese flavour' that retained the centrality of the actor using scenarios and improvisation and borrowing speech and movement conventions from jingju (Beijing opera). This excitement over the possibility of tongsu huaju serving as a hybrid alternative to the westernized huaju prompted enthusiastic discussions and a debate between two wenmingxi veterans, but ultimately ended with the subsumption of the last tongsu huaju company within the municipal huaju company - Shanghai People's Art Theatre - in 1960.

These two abortive attempts at huaju localization essentially bracketed modern Chinese theatre's phase of realist orthodoxy, as its third phase, which involved reincorporating Chinese theatre, started shortly after the end of the Cultural Revolution (1966-76), which was itself a lost decade for huaju. ${ }^{4}$ As such, they underscore the emerging and residual blind faith in realist theatre as the zenith of theatrical evolution, the ultimate path for both traditional and modern theatre. In this sense, the third phase of modern 
Asian theatre, starting from Japan's Little Theatre Movement of the 1960s that produced such prominent artists as Suzuki Tadashi and Ninagawa Yukio, represented a reaction against such a Eurocentric orientation. Intriguingly, the watershed moment that triggered the movement - the failed mass protest against the renewal of the Japanese-American Treaty of Mutual Cooperation and Security (Anpo) in 1960 - happened in the same year as tongsu huaju's disappearance as an independent genre. Such seeming coincidence further complicates the dominant narratives regarding the periodization of modern Asian theatre and forces us to examine such cross-currents at more granular levels.

With these issues in mind, I will examine, in the rest of this article, the brief rise and fall of tongsu huaju in Shanghai in the late 1950 and early 1960 s with a focus on its dramaturgy and performance, the debate over its utility, the policies that ultimately led to its demise, and the implications of the tongsu huaju phenomenon for the periodization of modern Asian theatre. I start with a section on the 1957 tongsu huaju festival in Shanghai, including a brief discussion of the naming of tongsu huaju in the 1940s as a popular (tongsu) and therefore less advanced form of huaju and of the 1956 national huaju festival that exposed the dire consequences of modern theatre's total rejection of traditional performance, which paved the way to the warm reception of tongsu huaju. The following sections focus on the debate over tongsu huaju's efficacy as a localized substitute for huaju. Those praising it as 'huaju with a strong Chinese flavour' included theatre scholars, officials and the wenmingxi veteran $\mathrm{Xu}$ Banmei, who also published his memoir on wenmingxi that year. On the opposing side was Ouyang Yuqian, another wenmingxi veteran and president of the Central Academy of Drama, who criticized tongsu huaju as utilizing 'methods adopted as the last resort in huaju's budding era'. While Ouyang was in the minority, his stature as a 'founding father of huaju' effectively shut down the debate. The final section discusses the genre's last creative success in 1959 with the play Sange muqian (Three Mothers), the subsequent merger of its only surviving company with the Shanghai People's Art Theatre in 1960 as its fangyan huaju (dialect spoken drama) company, and the company's eventual demise - together with the wenmingxi/tongsu huaju lineage - during the Cultural Revolution.

\section{The 1957 Shanghai Tongsu Huaju Festival}

Contrary to conventional belief, wenmingxi did not vanish in Shanghai after the $1910 .^{5}$ Instead, it lingered on as part of the popular entertainment that experienced a revival in the 1940s during the Japanese occupation, predominantly in the Lübao Juchang (Green Treasure Theatre) located on the sixth floor of the Xinxin Gongsi (Sun Sun Company Ltd) building. It was during this period that the term tongsu huaju was forced on wenmingxi as huaju practitioners simply refused to accept the genre as legitimate modern spoken drama. The wenmingxi veteran $\mathrm{Xu}$ Banmei recalls an unnamed and mysterious 'spokesperson', presumably representing huaju, warning the Green Treasure, 'Yours is wenmingxi and can't be called huaju; only what we perform is huaju'. This was followed by a film star cancelling an engagement and a novelist forbidding the company to adapt his novel even though he had given permission to huaju companies to do so. 
Realizing that they 'had already been sealed with the wenmingxi stamp', the company decided that,

to respect them as official huaju, we would definitely not infringe on this registered trademark. We would voluntarily drop one level and decided to be identified as 'tongsu huaju', to signify substandard huaju ... Using tongsu huaju made clear the class division; both sides lived in peace after that. ${ }^{6}$

Educated in Japan, Xu Banmei was one of the first wenmingxi actors and translators. As such, his bafflement and sarcasm at the contempt of huaju practitioners toward wenmingxi is obvious in these lines. Nevertheless, the term tongsu huaju was still not widely used at the time; wenmingxi remained the moniker for the form throughout the 1940s, as acknowledged by Xu and corroborated by contemporary publications. Indeed, a search of the online databases of Republican-era magazines and Shanghai's Shenbao newspaper returns only two titles with the term before the Communists took control of the city in May 1949, with the latter result, published in January of that year, showing tongsu huaju plays as part of regional opera. ${ }^{7}$ While the post-1949 authorities adopted the term tongsu huaju, they also treated the genre in the same category as regional genres, to be controlled, reformed and estranged from huaju proper. As such, tongsu huaju became a target of the xiqu reform campaign of the 1950s, which was built on the theatrical evolutionary model that had propelled much of the theatrical modernization efforts of the previous half-century. While the Western-style spoken drama huaju was significantly different from the total theatre of xiqu that rely on singing, dancing, miming and stage combat, as well as speaking, many of huaju's essential elements were considered the evolutionary goal for xiqu reform, including a well-written script; a directorcentred rehearsal system; design elements; and psychologically sound, Stanislavskybased performances. Within the xiqu system, jingju (Beijing opera) was considered the most sophisticated national form for regional genres to emulate. Consequently, tongsu huaju, as a speech-based regional genre that borrowed xiqu methods such as scenarios, improvisation and stylized acting, was not invited to the 1956 huaju festival and was categorized as a separate genre in the survey of national theatre genres published in 1957. In that survey, huaju was listed at the beginning, right after jingju, as being performed in 'every province and [provincial-level] municipality in the nation', while tongsu huaju was listed as being active in 'Jiangsu Province, Zhejiang Province and Shanghai', together with other regional genres from this area. ${ }^{8}$

However, this construction of huaju as a superior form to $x i q u$ was always contestable because of its lack of popularity among the average audience, although many in the huaju world trusted their practice as a 'scientific' form better aligned with modern theatre and more adept at performing social realities. After the establishment of the People's Republic of China in 1949, this claim was reinforced by the arrival of Soviet experts in the Stanislavsky system who, as part of Soviet assistance to China's socialist construction, taught in the Central Academy of Drama in Beijing and the Shanghai Theatre Academy and directed plays for top national theatres such as the Beijing People's Art Theatre. ${ }^{9}$ However, the real effect of the system on huaju dramaturgy and performance was severely challenged during the First National Huаju Observational and Performance Festival in 


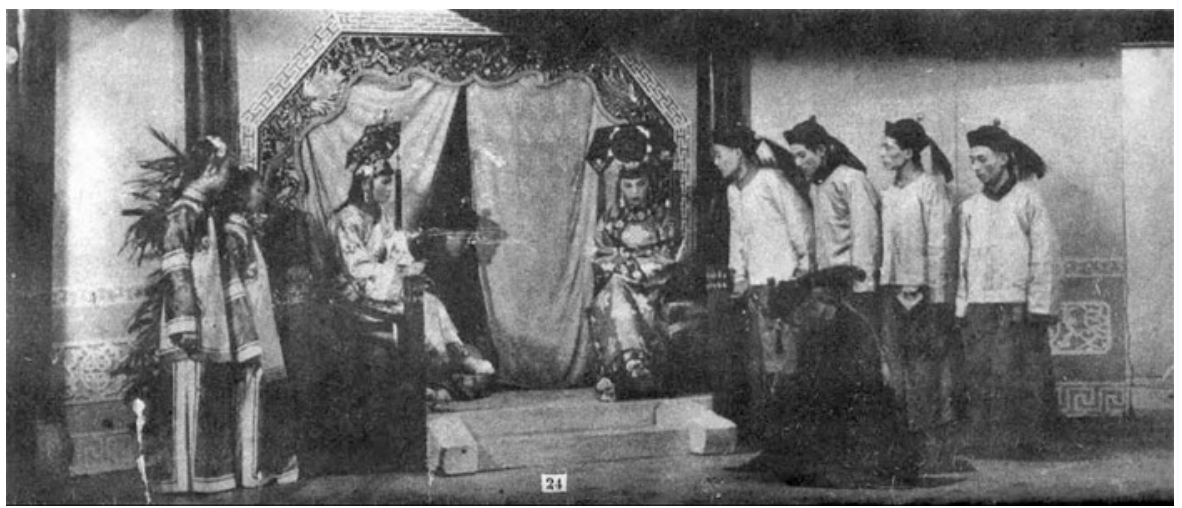

FIG. 1 The play Cixi taihou (Empress Dowager Cixi) identified as tongsu huaju (popular spoken drama). From anonymous, 'Difangxi' (Regional Operas), Dalu huabao (Grand China), 1, 1 (1949), pp. 24-25, here p. 24. Every effort has been made to secure necessary permissions to reproduce this image; however it has not been possible to trace the copyright holder. If any omissions are brought to our notice, we will be happy to include appropriate acknowledgements

March and April 1956, in Beijing. According to a candid report in the official publication of the National Dramatists' Association's Xiju bao (Theatre Gazette), a group of invited Soviet bloc theatre experts 'questioned the absence of signs of influence from traditional theatre in huaju' and its lack of musical accompaniment in the productions. Similarly, they criticized the formulaic dramaturgy that resulted in bland characters and onedimensional negative roles, thus restraining the creativity of the directors and actors, who were already plagued with naturalist and rigid performance. ${ }^{10}$ As the huaju director Mei Qian pointed out,

After studying the Stanislavsky system, some veteran actors grew extremely apprehensive of some of their past incorrect, exaggerated and hammy acting habits from old theatres. They wanted to succeed in simple and natural performance and strove to discard those exaggerations, which resulted in constant vigilance and underacting while onstage. This progress of curbing excessive acting has created another problem, which is, in their own words: 'I dare not move any more'. This constriction and vigilance have also created an impression in the audience, which is the lack of the character's selfawareness and self-confidence on the stage, an inability to trust oneself and earnestly live in the character's life. ${ }^{11}$

Such frank criticism coming from the Soviet 'big brothers', and painful admissions by the actors, led to intense introspection and acknowledgement, at least in some quarters, that huaju

is young, more influenced by Western theatre, and still needs nationalization and popularization, especially in terms of dramaturgy and performance ... Regardless of how scientific huaju practitioners regard their creative methodology, it is no more 
than self-righteousness if it deviates from national conventions of play reception and psychological demand. ${ }^{12}$

Such a sombre assessment of huaju among theatre scholars and officials clearly explains the visible excitement that greeted Shanghai's tongsu huaju festival between 8 and 12 January 1957 and a subsequent tour to Beijing in May. ${ }^{13}$

The festival included five wenmingxi classics and one new play titled Shouzu qingshen (Flesh and Blood). The five traditional plays were Zhenzhu ta (Pearl Pagoda), Hunbian (Marriage Turmoil), Zhang Wenxiang ci Ma (Zhang Wenxiang Assassinates Ma Xinyi), Guangxu yu Zhenfei (Emperor Guangxu and Consort Zhen), and Shehui zhong (A Bell against Social Injustice). From adaptations of melodramatic domestic novels and folk storytelling favourites to well-known Qing Dynasty court drama to an adapted Japanese shinpa play, this was representative subject matter for wenmingxi. In terms of the original creative process, most of these five repertoire pieces - with the exception of A Bell against Social Injustice from shinpa - started from scenarios (mubiao) that included characters, scene divisions and entrances and exits, with lines created by actors through improvisation. Through repeated performance, the lines were eventually settled into scripts. ${ }^{14}$ This unique method of play creation received a timely demonstration with Flesh and Blood, which was based on a news story - the separation and reunion of a brother and sister over twenty-five years - that was published on 17 and 18 December 1956. It took only ten days between publication of the story and its stage production.

The year 1957 also coincided with the fiftieth anniversary of modern Chinese theatre, which was officially determined to have begun with the 1907 Tokyo production of Heinu yutian lu (Black Slave's Cry to Heaven), a Chinese adaptation of Uncle Tom's Cabin. ${ }^{15}$ This occasion, together with the anxiety caused by the 1956 huaju festival, made the tongsu huaju performances a significant event, attracting over seventy observers from sixteen provinces and provincial-level municipalities, including Beijing. ${ }^{16}$ Furthermore, the productions - as a temporary Shanghai Tongsu Huaju Company - were invited to Beijing, Nanjing and other cities in May and June to perform most of the traditional plays. Tixiao yinyuan (Fate in Tears and Laughter), a popular play adapted from a 1930 bestseller, replaced A Bell against Social Injustice. Theatre Gazette published two production photographs in a short news item that assessed the genre: 'Tongsu huaju, aka xinju [new drama] (wenmingxi), has made positive contributions in the history of the Chinese huaju movement. After a period of obscurity, it has once again exhumed extraordinary radiance, attracting attention and appreciation'. ${ }^{17}$

\section{'Huaju with a strong Chinese flavour'}

These productions drew a great deal of excitement from a number of scholars and officials in charge of xiqu reform, including Deputy Director of the Cultural Ministry's Arts Division Ma Yanxiang, Shanghai xiqu reform officials He Man and Qian Yingyu (who were also critics and playwrights), and scholars from Shanghai (Zhao Mingyi) and Beijing (Chen Dingsha). ${ }^{18}$ There was a sense that this was the genre's last opportunity as the ages of the performers in Pearl Pagoda on the opening night ranged from forty-seven to eighty, the oldest being the actor Chen Wuwo, who had been away from the stage 


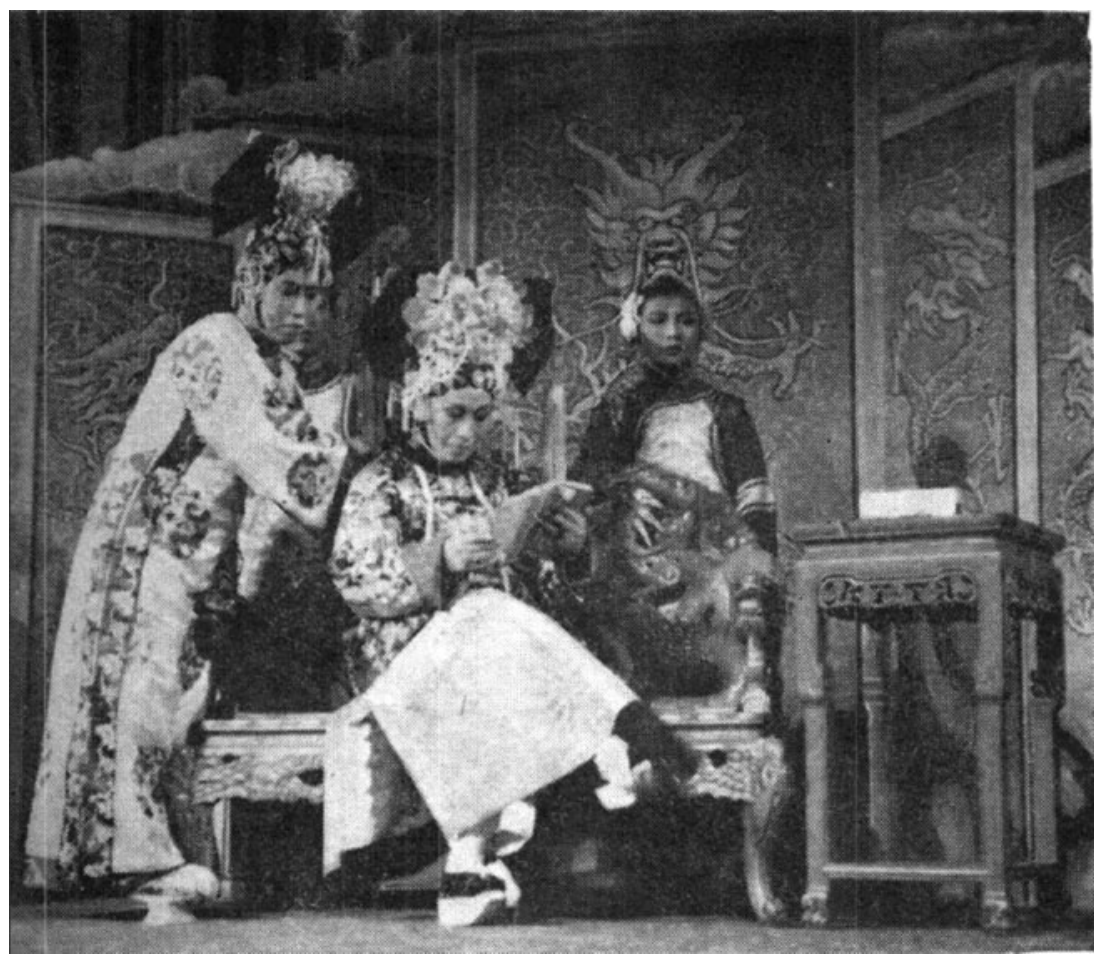

FIG. 2 A scene in Emperor Guangxu and Consort Zhen. Wang Meiyu as Empress Dowager Cixi (centre). From Xiju bao (Theatre Gazette), 12 (1957), p. 12. Courtesy of Shanghai Dramatic Arts Centre.

for thirty years. ${ }^{19}$ In the atmosphere of openness before the Anti-rightist Movement gathered pace later that year, Ma Yanxiang denounced the exclusion of tongsu huaju from huaju proper as 'radical tribalism in the arts and theatre circles' from both the May Fourth era that was 'obsessed with Western theatre' and the early 1950s, which 'only regarded the Stanislavsky system as authentic huaju and anything else as heresy'. ${ }^{20} \mathrm{He}$ even quoted Mao Zedong's support of the Hundred Flowers policy in a February 1957 speech: 'We think that it is harmful to the growth of art and science if administrative measures are used to impose one particular style of art or school of thought and to ban another'. ${ }^{21}$

Most significantly, Ma and other defenders saw tongsu huaju as 'huaju with a strong Chinese flavour, or huaju that has successfully inherited the national tradition'; in other words, a much-needed cure for the dramaturgical and performance deficiencies plaguing its younger, exclusively Western-oriented sibling. ${ }^{22}$ In terms of dramaturgy, they extolled tongsu huaju's ability to borrow from folk arts, traditional and popular novels and contemporary life, as well as to organize the narrative in the indigenous manner from the beginning to the end in double-digit shorter scenes, each ending with a cliffhanger. Beloved by the Chinese audience, such subject matter and narrative structure formed a sharp contrast to huaju's predominantly Western-style dramaturgy that often felt alien 


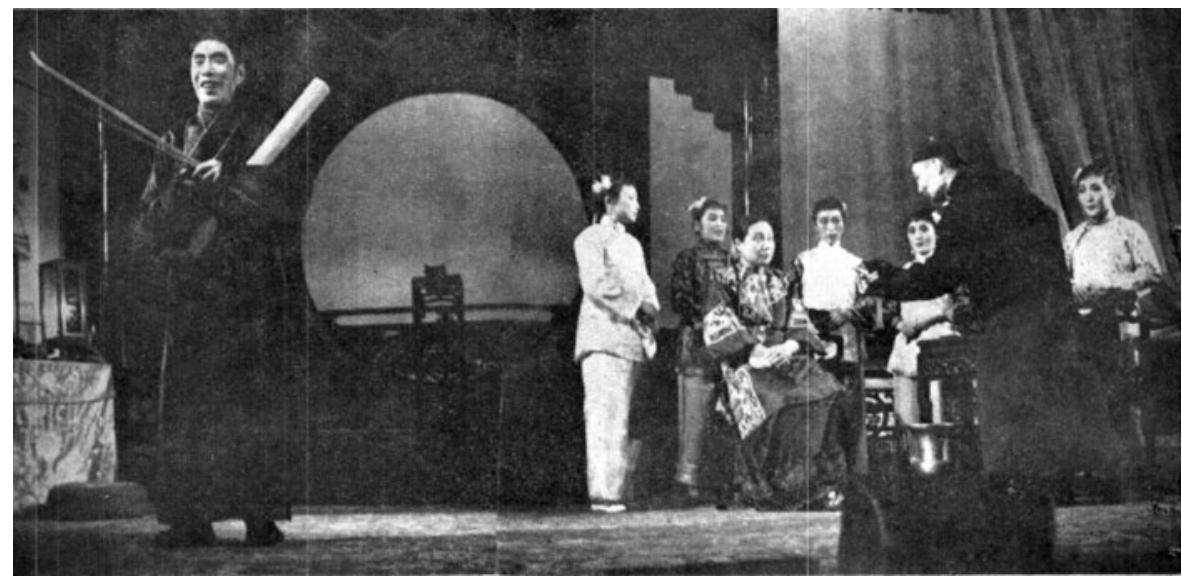

FIG. 3 A scene in Pearl Pagoda. Hu Huahun as Fang Qing (far left), Chen Xiafei as Mrs Chen (sitting), Chen Wuwo as Chen Lian (second from right), Wang Xueyan as Caiping (first from right). From Xiju bao (Theatre Gazette), 12 (1957), p. 12. Courtesy of Shanghai Dramatic Arts Centre.

to the Chinese audience accustomed to xiqu and folk art's linear structure. In contrast, huaju generally adopted a late point of attack (as in Greek tragedies, where the action of a play occurs near the end of a story); unified time, place and action; and lengthy acts with verbose expositions and transitions. As the huaju veteran and theatre professor Zhao Mingyi argued in a February 1957 article, 'Because of overly concentrated plot details, modern huaju makes it difficult to disentangle its many clues. Sometimes, a four-act play still needs exposition by the end of the second act, which makes it hard to figure out the centre of the event. ${ }^{23}$ Another issue, which was understandably elided by the authors for political reasons, was the predominance of historical and popular stories in tongsu huaju, in contrast to contemporary huaju's sole focus on the ideological conflicts among the workers, peasants and soldiers.

In term of characterization, these plays also followed the xiqu tradition of clear contrasts between good and evil that elicit strong reactions from the audience. Such character contrast can be found in the play Pearl Pagoda, which tells the story of a scholar, Fang Qing, who, after the downfall of his family, seeks help from his aunt, Mrs Chen, only to be coldly rejected by the latter, who has, just before Fang's entrance, boasted of the extraordinary wealth of her maiden home. Fortunately, Fang is helped by Chen's daughter Cui'e and eventually succeeds in the civil service examination, upon which he returns to Chen's family disguised as a Daoist monk, sings a ballad (daoqing, see Fig. 3) to shame his aunt, and marries his cousin Cui'e. Shanghai official and critic Qian Yingyu praised the play's contrastive technique, which was well known to the Chinese audience: 'Mrs Chen's snobbish vanity must be coupled with [her husband] Inspector General Chen's kind uprightness, Miss Chen's gentle kindness with Fang Qing's pedantic arrogance, [the maid] Caiping's adroit sharpness with [another maid] Hongyun's nasty meanness, all in pairs to set off and complement each other' ${ }^{24}$ 


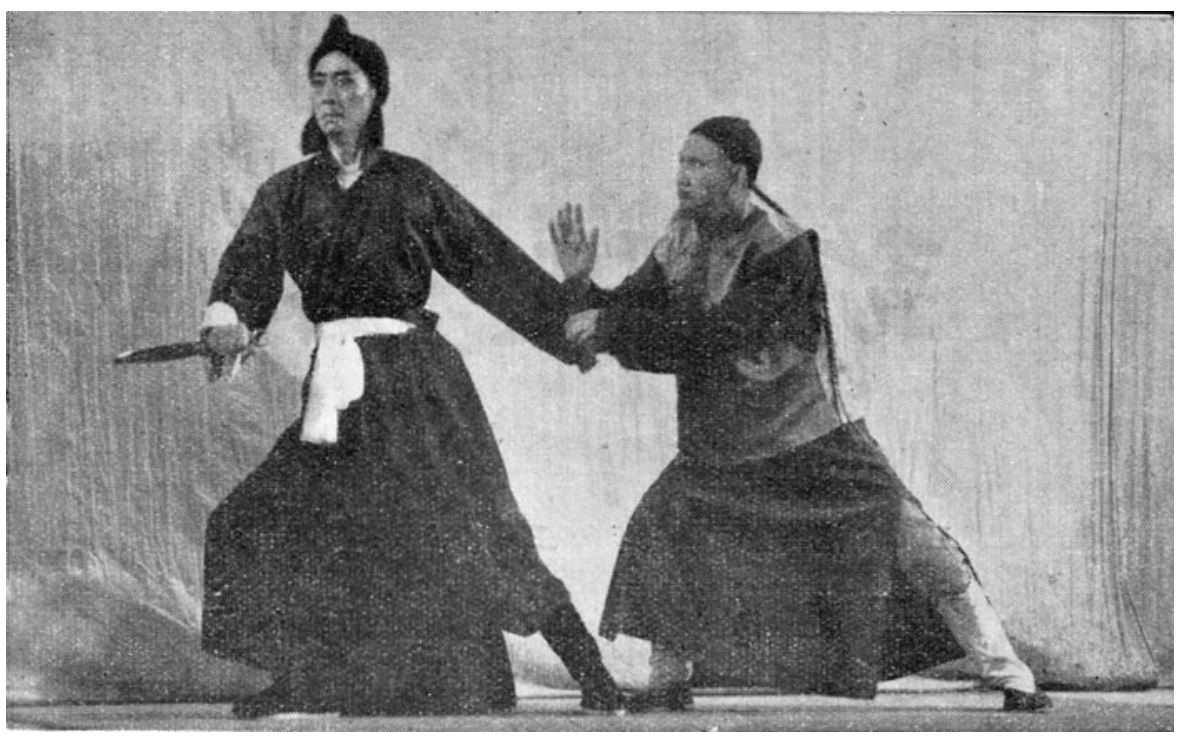

FIG. 4 Wang Manjun strikes a jingju-style pose as Zhang Wenxiang (left) in Zhang Wenxiang Assassinates Ma Xinyi. From Shanghaishi Tongsu Huaju Tuan xunhui yanchu (Shanghai Popular Spoken Drama Company Touring Performance Program), 1957. Courtesy of Shanghai Dramatic Arts Centre.

Much of the characterization resulted from a performance style that, as Zhao pointed out in a May article published in the authoritative Wenyi bao (Literature and Arts Gazette), 'was profoundly connected in terms of speech and movement to our national traditional theatre's performance conventions'. This phenomenon was made apparent by the actors aged over forty at the time, whose style contrasted sharply with that of their younger counterparts, who had little tongsu huaju experience and exhibited more influence of Western-style huaju. Zhao provided two examples:

Comrade Tian Chi's performance of the character Dou Yihu [a bandit in Zhang Wenxiang Assassinates Ma Xinyi] makes the audience excited about his bold gestures, tones and actions, all of which were conventionalized. Some people said that the rhythm of his actions would have fit perfectly even if percussion beats were added. Yet we completely admitted he was performing huaju, completely lifelike. In another example, in An Dehai, the character Shandong Envoy acted by old Mr Qin Haha ... was also performed in a very conventionalized manner, which we not only did not feel uncomfortable with, but on the contrary felt a sense of endearment and familiarity. If this is developed from our traditional theatrical performance techniques, then I think that, amidst our call today for huaju to learn from national heritage, this is something particularly worthy of attention and study. I believe that there truly exists our national traditional performance techniques within the performance art of $x i n j u$ [new drama]. ${ }^{25}$

Another surprise finding by the writers was tongsu huaju's 'appropriate adoption of traditional expressive methods in the life of modern people. We do not see them as 
discordant; some of them even feel extraordinarily comfortable'. ${ }^{26}$ At the core of the genre's Chineseness is the preservation of a sense of theatricality, of play, or of what $\mathrm{He}$ Man called wutai quwei ('delight of the stage'), for which he offered a seemingly minor but nevertheless telling example from Pearl Pagoda. The example comes early in the play when the maid Caiping tries to keep the downtrodden and angered Fang from leaving the Chen house:

\begin{abstract}
She knows a poor person does not have many possessions, except for the bundle and umbrella he carries. If she can keep them, she can detain Fang Qing. Thus, she walks over, criticizing the snobbish maid Hongyun for throwing Fang's bundle and umbrella to the floor. Meanwhile, she takes them from Fang, mimics Hongyun's actions, and seamlessly takes away the bundle and umbrella, leaving Fang with no choice but to stay. Through such a delightful performance, the actress has left the audience with an extraordinarily upright, clever and dexterous character. ${ }^{27}$
\end{abstract}

Here, the actress's adroit and playful combination of movement and speech to elongate and highlight an easily ignored moment is highly reminiscent of xiqu theatricality, which is made even more obvious in the follow up: Fang becomes anxious for fear of losing his umbrella and asks for it back, to which Caiping rejoins. 'I'm afraid I can't obey. If I did, you'd be gone. Leave it to me for now and stay for a while.' Realizing that he has been tricked, Fang bursts in laughter: 'Haha, such a naughty girl. I fell for it!' 28 This is a typical comic exchange from popular jingju plays such as Hongniang, which is also about a maid helping the union of her mistress and a young scholar. ${ }^{29}$ This sense of play - as opposed to the pursuit of Stanislavskian interior experience - again links to the premodern core of xiqu performance before social-critical realism and a vulgarized understanding of Stanislavsky significantly limited huaju to timid naturalism onstage, as demonstrated in the quote above from Mei Qian.

Consequently, these scholars and officials saw scenario plays as the core of the genre's creative process, which not only allowed for the prompt staging of contemporary events but also granted the performers a vital role in the artistic process. Several of them pointed toward Flesh and Blood as an example of the genre's capacity for quickly staging current events as its 'outstanding advantage' over huaju. ${ }^{30}$ Ma Yanxiang pointed out that not all tongsu huaju plays were improvised, since plays such as Zhang Wenxiang Assassinates Ma Xinyi had scripts. The difference, though, was that the script was not written by one playwright but created collectively by the actors through repeated performance. Calling tongsu huaju 'Western theatre in form but with a clear national style', Ma declared, 'To me, the reason behind the popular appeal [tongsu] of tongsu huaju is exactly this unique creative method. Denying the scenario system as a creative methodology in fact denies tongsu huaju's artistic characteristics, thus denying its

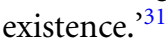

This seemingly euphoric assessment of the genre prompted Xu Banmei to write a pointed article to challenge the elite misconceptions of wenmingxi, starting directly from the centrality of the actor: 


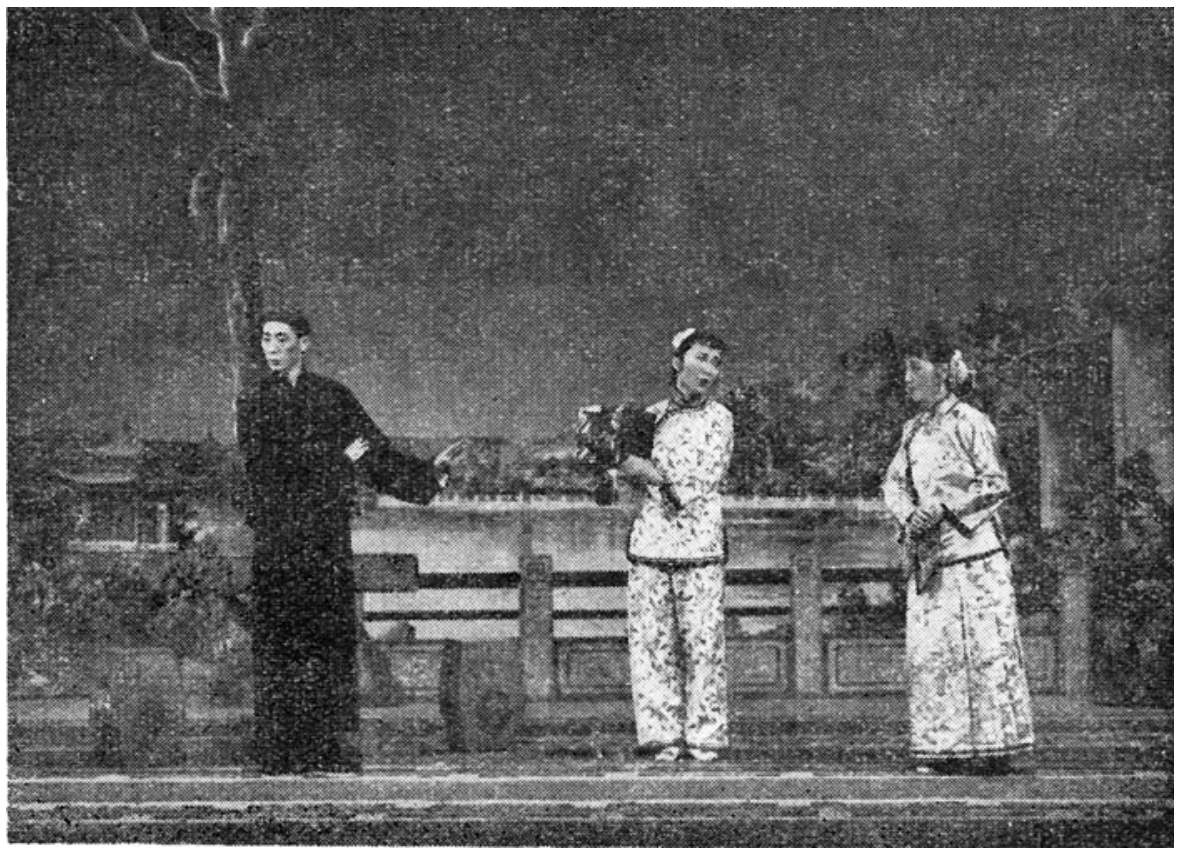

FIG. 5 A scene from Pearl Pagoda. From left to right: Fang Qing (Wang Manjun), Caiping (Wang Xueyan), and Cui'e (Zhang Caixia). From Shanghaishi Tongsu Huaju Tuan xunhui yanchu (Shanghai Popular Spoken Drama Company Touring Performance Program), 1957. Courtesy of Shanghai Dramatic Arts Centre.

Tongsu huaju relies on the performer for everything, and does not use the script or the director. Actors create not only the characters but also the lines and everything else ... By contrast, once there is a script and a director, the actors would at times feel limited.

He further illustrates the point by quoting a playwright: 'The improvised dialogues from tongsu huaju actors are more lively than those from our pens'. Finally, he delivers a full-throated defence of the scenario's timeliness, comparing the possibility of staging a contemporary event within three days to the year-plus cycle of playwriting and rehearsal for huaju that inevitably results in the loss of topicality by the time it opens. Such contrast 'entirely relies on the power of the scenario'. ${ }^{32}$ Before the article was published in August 1957, Xu also published his book-length memoir on wenmingxi, which is filled with fond memories of scenario plays, calling it 'futuristic-style collective playwriting, ${ }^{33}$

At this point, it is tempting to speculate why, if scenario plays were so timely, they were not adopted for propaganda purposes, as was common for amateur and professional performances at the time. The answer may be one of practicality due to the decades of attrition of tongsu huaju performers as opposed to the proliferation of huaju ideology, dramaturgy and performance techniques that had been increasingly popular in amateur and professional spoken theatre since the 1920s. It may also lie in the ideological blind 
spot that assigned such dramaturgy with backward ideology, and it is these ideological and dramaturgical debates that I shall now go on to discuss.

\section{'Methods adopted as the last resort in Huaju's budding era'}

Even at the height of this liberal era, mainstream sentiment was still firmly rooted in the evolutionary camp that deemed script- and director-centred rehearsal the way of the future. This is the sentiment of an article published in Theatre Gazette at the beginning of 1957 that, while criticizing earlier local measures aimed at eradicating scenario xiqu plays and acknowledging their tremendous popularity when allowed onstage that year, nevertheless declared that "outline plays" [tigangxi] should be gradually converted to "script plays" [jubenxi]'. 34

A more systematic critique of wenmingxis usage of scenario plays came from Ouyang Yuqian, who had played Eliza's son Hailey in the 1907 Tokyo Black Slave's Cry to Heaven by the Chunliu She (Spring Willow Society), which, unlike almost all other wenmingxi companies, aspired to use complete scripts even as eventual competition in Shanghai forced it to embrace scenarios and improvisation. ${ }^{35}$ Regarded as the most authoritative voice on wenmingxi, Ouyang wrote two long articles in 1957, one on the Spring Willow Society and one on wenmingxi in general, which were published the following February in the first volume of huaju fifty-year commemorative essays. ${ }^{36}$ Prior to that, he had published the Spring Willow article in issue 3 of Xiju luncong (Theatre Forum) in August 1957, but chose to publish only the 'Tan mubiaoxi' ('On scenario plays') section of the complete wenmingxi article, which was written in August, in issue 4 of Theatre Forum in November. As such, Ouyang's eagerness to 'set the record straight', as it were, on scenario plays after the wave of excitement that sought to establish tongsu huaju as huaju's nationalized counterpart, is palpable.

As the only wenmingxi actor who had successfully transitioned to huaju, had performed in jingju, and was long involved in xiqu reform both in Shanghai and with guiju (Guangxi opera) in the southwestern hinterland during the Japanese invasion (1937-45), Ouyang was lauded as one of huaju's three 'founding fathers'. On the other hand, it is critical to remember that his objection to scenario plays was rooted in the fundamental difference between the Spring Willow Society, which followed Japanese shinpa and used more scripts, and the other, more popular wenmingxi groups that relied on scenarios and improvisation. ${ }^{37}$ Therefore it is no surprise that while Ouyang praised some wenmingxi plays with scripts from repeated performance, he methodically rebutted the arguments of Xu and others, especially on the efficacy of scenarios. To him, the fact that wenmingxi performance seemed more natural did not result from the scenario system because 'they could have been even better with scripts'. As president of the Central Academy of Drama that hosted several Soviet experts teaching the Stanislavsky system, Ouyang's definition of drama exhibits a decidedly Stanislavskian tinge: 'The play must be well organized, with a theme, a through-line of action, appropriate dialogue, and a super task'. ${ }^{38}$

Such a dramaturgical foundation indeed left no room for scenario plays. For Ouyang, their speed in staging current events is only 'limited to reflecting reality ... and will never become drama'. A wide variety of subject matter 
is not a capacity limited to scenario plays as there is nothing that stops scripts from using all types of subject matter ... and there is no limit to the topics of modern huaju. There is no rationale behind the belief that using scenarios instead of scripts results in a wide variety of subject matter.

To the arguments that using the script restricts the actor's freedom onstage, leading to unnatural dialogue or even declamation, Ouyang counters with his definition of drama quoted above, stressing, 'While the blueprints by the dramatists cannot include everything onstage and stage actions are primarily achieved by actors, the lack of a script is simply not a possibility. Without a script there is no basis'. As for the follow-up argument that in scenario plays actors can complement the playwright and enrich the play with their own life experience, Ouyang calls it 'unrealistic wishful thinking': 'Since the actor does not necessarily have more life experience than the playwright and most of them are only familiar with one or two types of people's lives, how do they help the playwright create new characters?' He concludes with the plea,

To make theatrical art both elegant and popular, to make it enjoyable to the masses, there should be above all a good script. If we do not help tongsu huaju evolve in this aspect, but instead only reminisce about the past and repeat today the methods adopted as the last resort in its budding era, that would not be helpful and could only be a disservice. ${ }^{39}$

Judging from the fact that there was no more discussion about tongsu huaju's efficacy after Ouyang's article, it seems safe to conclude that Ouyang, with his authority, effectively slammed the door on the short-lived tongsu huaju euphoria, with a top-down argument of the playwright's supremacy that removed the performer from the creative process. Undoubtedly heartfelt from his perspective, his arguments are not watertight. One example is his statement that huaju was equally capable of a wide variety of subject matter when he must have been well aware of huaju's severely limited thematic focuses, as most acutely exhibited in the 1956 festival. As one critic wrote in July 1957, the huaju plays of the era predominantly focused on only three thematic areas: 'Workers' plays: struggle between advanced and backward ideologies; peasants' plays: struggle between joining or not joining the commune; and army plays: military struggle between enemy armies and our own. ${ }^{40}$ Similarly, when he stated that actors did not necessarily have more life experience, he elided the fact that wenmingxi actors were based on role categories just like in jingju, which allowed them to create only characters of the type they specialized in, such as a romantic lead, sharp-tongued woman, or clown. Consequently this system often resulted in multiple experts within a cast for characters of different types in contrast to the omnipotence of the playwright, who creates all characters. In fact, in 'On wenmingxi', which includes the section 'On scenario plays', Ouyang praised several wenmingxi actors for 'creating colourful characters' in the play Konggu lan (Orchid of the Hollow Valley), which 'many audience members watched several times and some could even recite the best lines'. ${ }^{41}$ As such, Ouyang's criticism of scenario plays, while not without merit, was nevertheless an ideological rehashing of the evolutionary argument against wenmingxis 
hybridity, an article of faith among huaju practitioners, who had condemned wenmingxi as the debased Other since the 1920s. ${ }^{42}$

\section{Tongsu huaju in Shanghai after 1957}

Combined with the Anti-rightist Campaign starting in July 1957 that effectively ended the year-long liberal policies of xiqu reform, Ouyang's article precluded the possibility of tongsu huaju serving as a viable, national alternative to the Westernized huaju. At the same time, tongsu huaju's brief efflorescence did attract the attention of Shanghai's cultural authorities to its precarious state. As a result, twenty-one plays dating from the wenmingxi era were transcribed from the actors' memories and published in seven volumes between 1959 and 1962 as part of the national campaign to preserve traditional plays. ${ }^{43}$ In terms of organization, the remaining three tongsu huaju companies in Shanghai - the Datong (Great Unity), Xinsheng (New Life), and Haiyan (Sea Swallow) - merged into a new company called the Zhaoyang Tongsu Huaju Tuan (Morning Sun Popular Spoken Drama Company), which performed on a small stage in the variety entertainment venue Dashijie (Great World). ${ }^{44}$

In 1959, the Morning Sun Company created another sensation with the play Sange muqin (Three Mothers), receiving high praise in a Theatre Gazette article by Yao Shixiao, secretary general of the Shanghai Dramatists' Association. Specifically, Yao lauded it as an exemplarily combined effort between tongsu huaju artists and a huaju director, known at the time as a 'new literature and arts worker' (xin wenyi gongzuozhe), a term used to denote modern educated playwrights, directors, composers and designers working with xiqu companies. It was later adapted into a film with the same actors. Written by the play's lead actress, Wu Saiwen, with collective contributions by the company, the play tells a quarter-century-long story (1933-58) of the son (later called Jianhua) of a poor worker, Wang Zhengting. The son is first forcibly adopted as a baby by the concubine of a rich capitalist, then brought up by the concubine's maid Zhou Ma (performed by Wu), and eventually reunited with his birth mother in new China. With a meandering structure full of twists and turns typical of tongsu huaju, the play, while not without elements of class consciousness, is nevertheless focused on the lives of ordinary city dwellers in a way that is decidedly different from the stereotypical drama of the era. In sharp contrast to the typical huaju structure, built around a story and relying on expositions for plot background and character relations, its nine acts follow the traditional storytelling technique, starting from Jianhua's forced adoption and ending, twenty-five years later, with the family reunion.

It is also filled with wonderful details of average people's lives and worries, contained in pithy lines that validate $\mathrm{Xu}$ Banmei's contention about the actors' creativity. For example, in Act V, the thirteen-year-old Jianhua apprentices in a tailor shop in Shanghai when the mistress asks him to go and buy some sesame oil. Her daughter Zhaodi, who later becomes Jianhua's fiancé and is protecting him even now from her mother's exploitation, volunteers for the errand with the excuse that Jianhua is rushing to finish a piece of clothing, which results in the mistress, loath to have her daughter perform the task, grabbing the oil bottle and cash from Jianhua's hands and going out herself. Another 


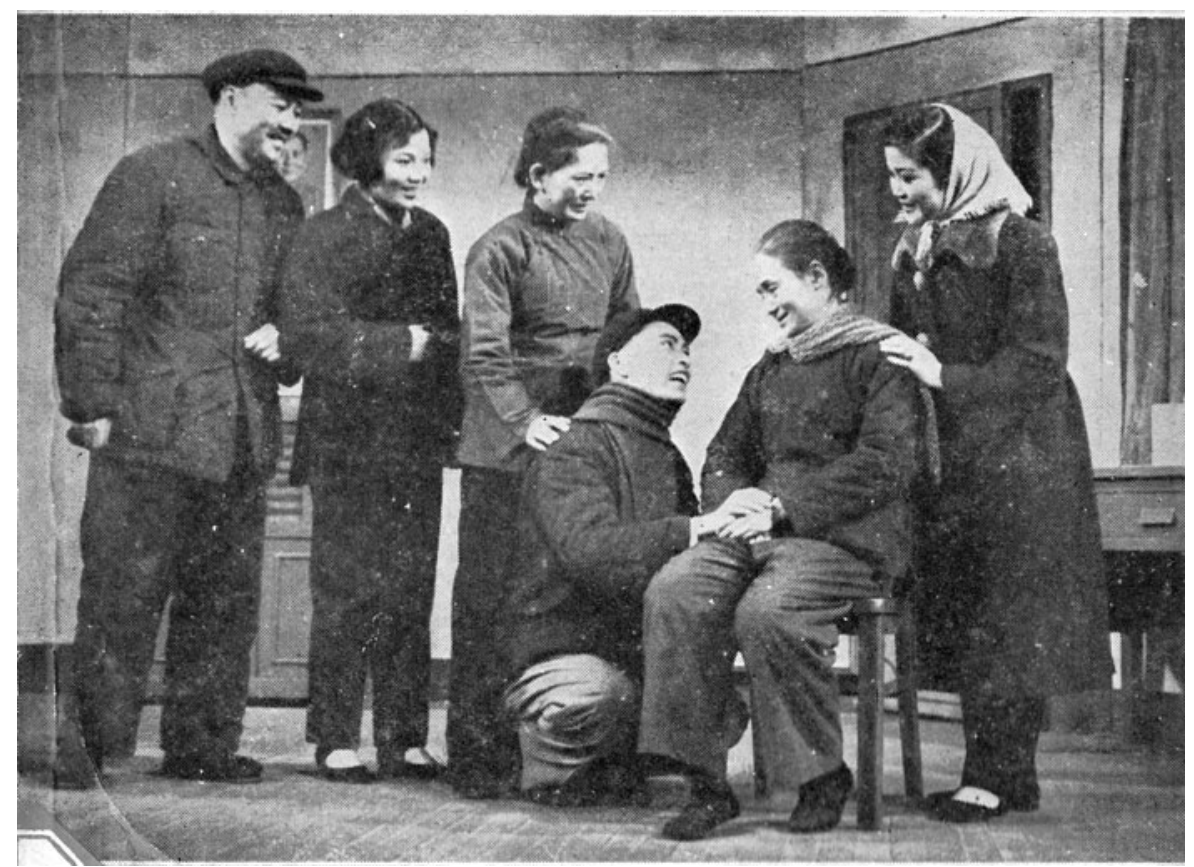

FIG. 6 Final scene of Three Mothers, depicting the son, Jianhua, kneeling in front of his adopted mother, Zhou Ma, together with his biological family (behind him) and fiancée (behind Zhou). From the cover of Sange muqin (Three Mothers) (Shanghai: Shanghai wenyi chubanshe, 1959). Courtesy of Shanghai Dramatic Arts Centre.

example of detailed characterization can be found in Act VIII, set in 1958. Zhou Ma, who has been back in her ancestral home in Suzhou, is preparing to go to Wuhan to live with Jianhua when she learns from a policeman that Wang Zhengting's family, also living in Wuhan, is looking for their lost son. After some hesitation, she tells the policeman of Jianhua's identity and promises to assist in reuniting the family. At this point, Zhaodi arrives from Shanghai ready to accompany Zhou Ma to Wuhan. Here, through a series of detailed actions, Wu Saiwen masterfully performs Zhou Ma's inner conflict, fearing she will lose Jianhua forever, and worrying about the possibility of Zhaodi reacting negatively to Jianhua's identity as an adopted child:

ZHAODI: Let me wash these two pieces of clothing so they'll be dry by tomorrow. You go and pack, I'll do the laundry.

ZHOU MA: (replies absent-mindedly) Oh, all right.

(ZHAODI turns to take off her coat, then turns around and finds ZHOU MA still standing there motionless.)

ZHAODI: Hey, Mum, go and pack! 
ZHOU MA: (as if shocked awake) Oh! Oh! (Randomly picks up a thermos from the table.)

ZHAODI: Mum, this is a thermos! (Takes the thermos from ZHOU MA's hand.) Mum, go and pack.

ZHOU MA: Oh, oh. (Turns around and puts a stool on the bed.)

ZHAODI (realizes ZHOU MA is preoccupied) Mum, are you all right? (Sees ZHOU MA holding a sweater.) Mum, what's this? (Takes it over to have a look.)

ZHOU MA: Jianhua's sweater from when he was a child. ${ }^{45}$

These are the type of life-like details, without explicit ideological elevations by the playwright, that made tongsu huaju an audience favorite.

At the same time, it is telling that the Theatre Gazette reviewer, Yao Shixiao, singled out Zhou Ma's hesitation before telling the policeman about Jianhua as the play's only flaw, criticizing the detail for 'showing too much reluctance to part with her son, which reduces the character's quality as well as the play's ideological merit'. ${ }^{46}$ It is ironic for an article touting the play's average characters to fault it for lacking proper ideological awareness, for creating a mother who reveals the slightest hesitation and fear for losing her only son of twenty-plus years. Such a contradiction epitomizes the ideological blind spot of the theatre officials that left diminishing space for tongsu huaju as a genre for average city dwellers, foreshadowing the headwind that eventually engulfed the genre. More ominously, coming from Yao as the secretary general of the Shanghai Dramatists' Association, the article pointedly ends with an emphasis on the director's significance to the genre:

As the play's director, Comrade Wu Li from Shanghai Theatre Academy provided significant assistance in its performance and script revision. From the perspective of performance alone, under the director's centralized vision, the production showed uniformity in performance. In past tongsu huaju productions, we often witnessed unplanned improvisations, at times even extreme chaos, which often destroyed the integrity of the production. But Three Mothers' direction was very crisp, and the director managed to accentuate the strength of the tongsu huaju actors, resulting in obvious progress in performance. This again proves that the participation of new literature and arts workers is critical to the reform of the old theatrical genres. ${ }^{47}$

This faith in the director's centrality in the evolution of tongsu huaju soon led to the loss of creative independence for the genre's actors.

In 1960, the Zhaoyang Tongsu Huaju Company, together with the Mifeng Huaji Jutuan (Bee Farcical Theatre Company), joined the municipal Shanghai People's Art Theatre as its popular spoken drama and farce companies, although tongsu huaju was changed to fangyan huaju (dialect spoken drama) from this point onward, further ghettoizing the genre. ${ }^{48}$ The idea of fangyan huaju as tongsu huaju's direction of growth was first proposed by Chen Dingsha, who had come to the January 1957 festival from 
Beijing as an assistant to Zhang Geng, deputy director of the Traditional Theatre Research Institute and ardent defender of xiqu against radical reform efforts. In an article published in People's Daily on 29 January 1957, Chen highly praised the genre as 'deeply reflective of the national art tradition in dramaturgical structure, directorial techniques, performance style and stage apparatus', and its scenario system as speedy in expressing current events and advantageous for the growth of acting skills. In the final section, he focused on dialect:

A major reason behind tongsu huaju's popularity is its mixture of Mandarin and dialect. As a huaju genre, this should be one of its characteristics. For the several plays I saw this time, I think the use of dialect not only drew the audience close, but also often enabled the actors to unleash their strength through dialect, thus making their characters especially vibrant. On the contrary, when they spoke Mandarin they sometimes completely lost the lustre of life, their remarks being simply dry and boring. When everyone onstage was speaking Mandarin, we felt their performance was at a much lower level compared to huaju. Personally, I believe a part of tongsu huaju might as well grow in the direction of fangyan huaju, with local characteristics. ${ }^{49}$

Obviously Chen's proposal was based on a desire to protect fangyan huaju and maintain huaju's diversity. In fact, the Three Mothers script was already written - and without doubt delivered - in Shanghai dialect, a clear sign that Chen's proposal had already been internalized by the tongsu huaju actors. The problem with the proposal, however, is the pecking order that placed fangyan huaju on an even lower rung on the evolutionary ladder. While it was entirely possible that the tongsu huaju actors were less well trained in stage diction than huaju actors coming out of the Stanislavsky system, Chen nevertheless ignored the fact that the artificial delivery style of huaju actors had largely contributed to huaju's alienation from the average audience through its emphasis on enunciation and tonal perfection (zizheng qiangyuan - 'pronounce characters correctly and tones roundly') as well as modulation and cadence (yiyang duncuo - 'falling, rising, pauses, breaks'). In contrast, at least judging from the 1959 film of Three Mothers, the tongsu huaju actors spoke in perfect but more casual Mandarin much closer to everyday speech. Even if we account for the possibility of toning down the stage speech for film, these actors' deliveries were simply far less artificial than those of their huaju counterparts. While Chen's other rationale - the preservation of local colour - was certainly important for the sake of huaju diversity, making tongsu huaju take the subordinate role as fangyan huajugiven the genre's history of forced subordination to huaju - was indeed tantamount to a ghettoizing strategy. Indeed, while the name could further accentuate the genre's special appeal to the local Shanghai audience, that appeal was already accounted for in the name tongsu huaju, and the actors were free to perform in dialect - as they obviously did in Three Mothers - without the ghettoizing name change. Here, the ideology of the modern monoglot standard - 'one society, one culture, one language', as delineated by Richard Bauman and Charles L. Briggs - has assigned fangyan huaju an intrinsically inferior position to the Mandarin-speaking huaju even as Chen meant to object to its hegemony. ${ }^{50}$ 
Indeed, further diminishing tongsu huaju into fangyan huaju effectively ended the lineage of wenmingxi as a living theatrical genre up until 1960 and consigned it to museum status. Apart from Three Mothers and another play, Hongxing chuqiang (Apricot Flower Flaming Out over the Wall) (1960), that was also created before the merger, the fangyan huaju company only performed three new plays. Unsurprisingly, these plays were far from the genre's middle-class roots as they were adapted from huaju and staged after 1963 during the heightened ideological environment leading up to the Cultural Revolution in 1966: Duanlian (Tempered in Struggle), Qingnian zhenchayuan (The Young Scout), and Longjiang song (Ode to the Dragon River). During the three relatively peaceful years between 1960 and 1963, instead of new play creation, major energy was devoted to consolidating six (out of a planned ten) existing tongsu huaju plays: Heinu hen (The Regret of Black Slaves), based on Black Slave's Cry to Heaven; Zhang Wenxiang Assassinates Ma Xinyi; Pearl Pagoda; Zhizhan An Dehai (Executing An Dehai by Strategy); Jinqian shijie (The World of Money); and Fate in Tears and Laughter. ${ }^{51}$

After the Cultural Revolution (1966-76) ended, the farcical Shanghai Huajixi Company was restored, but its dialect huaju counterpart was not, signifying a final death knell to the nationalized first form of modern Chinese theatre, starting from wenmingxi, through tongsu huaju, and finally ending in fangyan huaju.

\section{Tongsu huaju and the narrative of periodization in modern Asian theatre}

While preparing for his production of Trojan Women in 1974, Suzuki Tadashi, who may be taken as a representative director of the third, intercultural phase of modern Asian theatre, discussed the difference between his production and Mishima Yukio's play Madame de Sade, a key text of Japan's second, westernizing phase of modern theatre, shingeki ('new drama'). According to Frank Hoff, Suzuki deemed Mishima's play 'a European play written by a Japanese to be staged in the Shingeki mode. Mishima admired this unique mode of production and acting; it demonstrated the intellectual superiority of Japanese who, though a race apart, were simultaneously conversant with European things'.$^{52}$ In other words, as Japan's equivalent of huaju, shingeki considered being 'conversant with European things' a sign of Japanese 'intellectual superiority', just as Ouyang Yuqian considered his system-inspired definition of drama the paramount purpose for huaju. Suzuki, then, deliberately defined his aesthetic - and by extension much of the intercultural phase of modern Asian theatre - as the opposite of Mishima's (and of Ouyang's and others like them). This new aesthetic is

characteristic of the way Europeans live in their own part of the world - with the unique means of bodily expressiveness available to Japanese; to incorporate it according to a Japanese theatrical sensibility ... by keeping the production of a Greek play within the category of 'drama' and by not rendering it in the normal way that Shingeki would, that is to say as Western translation theater. ${ }^{53}$

While tongsu huaju, as a remnant of wenmingxi, was different in many ways from Suzuki's interculturalism, the 1957 excitement over its Chineseness shares several key elements with Suzuki's approach, namely employing physical expressions unique to 
Asian bodies, indigenous theatrical sensibilities, and keeping the plays' theatricality as 'drama' instead of translated Western text. Deviation from these principles largely doomed shingeki, huaju and similar endeavours of this period in other regions such as South East Asia, where similar practices were labelled by James R. Brandon "'nonpopular" theatre'. ${ }^{54}$

The contemporaneous rise of Japan's Little Theatre movement, which shaped Suzuki, as well as the demise of tongsu huaju in the 1960s, serve as powerful reminders of the dominant influence of the sociopolitical environment on theatre. While tongsu huaju was still practised within a context of modern Western cultural dominance (albeit through the Soviet Union), the Little Theatre movement that arose from the antiAnpo movement ushered in postcolonial, postmodern Asian theatre. In other words, while intercultural theatre operated in an era favouring the rediscovery of indigenous theatricality, tongsu huaju was still against the formidable Western-dominant modern ideology despite Cold War politics. As such, the case of tongsu huaju has allowed us to significantly complicate the narrative of periodization in modern Asian theatre.

NOTES

1 Kevin J. Wetmore Jr, Siyuan Liu and Erin B. Mee, Modern Asian Theatre and Performance 1900-2000 (New York: Bloomsbury Methuen Drama, 2014), pp. 12-14.

2 For more on wenmingxi see Siyuan Liu, Performing Hybridity in Colonial-Modern China (New York: Palgrave Macmillan, 2013).

3 Siyuan Liu, 'The Cross Currents of Modern Theatre and China's National Theatre Movement of 1926', Asian Theatre Journal 33, 1 (2016), pp. 1-35.

4 There were a few propaganda huaju pieces at the beginning and toward the end of the Cultural Revolution, but not much else. See Wetmore, Liu and Mee, Modern Asian Theatre, pp. 110-11.

5 Discussions of wenmingxi generally stop at the end of the 1910s, including my book on the subject, Performing Hybridity in Colonial-Modern China.

6 Xu Banmei, Huaju chuangshiqi huiyilu (Memoir of Spoken Drama's Founding Era) (Beijing: Zhongguo xiju chubanshe, 1957), pp. 125-6. All translations are my own unless otherwise indicated.

7 Botao, 'Lundun mengnan: liumu tongsu huaju' (Striken by Disaster in London: Popular Spoken Drama in Six Acts), Minjian wenyi (Folk Literature and Arts) 3, 5 (1935), pp. 7-23; Anonymous, 'Difangxi' (Regional Operas), Dalu huabao (Grand China) 1, 1 (1949), pp. 24-5.

8 Su Yi, 'Quanguo juzhong chubu tongi' (A Preliminary Survey of National Theatrical Genres), Xiju luncong (Theatre Forum) 1 (1957), pp. 215, 218.

9 See Siyuan Liu, 'Towards a Chinese School of Performance and Directing: Jiao Juyin', Chapter 6 of Jonathan Pitches and Stefan Aquilina, eds., Stanislavsky in the World: The System and Its Transformations across Continents (London: Methuen, 2017), pp. 149-65; and Jonathan Pitches and Ruru Li, 'Stanislavsky with Chinese Characteristics: How the System was Introduced into China', Chapter 7 of ibid., pp. 166-95.

10 Anonymous, 'Zhongwai xijujia chengzhi de jiaotan' (Sincere Dialogue betwen Chinese and Foreign Dramatists), Xiju bao (Theatre Gazette), 4 (1956), pp. 34-5.

11 Mei Qian, 'Guanmo suibi size' (Four Notes from Observation), Xiju bao (Theatre Gazette), 4 (1957), p. 31.

12 Chen Dingsha, 'Kan Shanghai tongsu huaju huiyan' (Watching Shanghai Popular Spoken Drama Festival), Renmin ribao (People's Daily), 29 January 1957, p. 7.

13 Gu Naijin, 'Shanghai xiqu yanchu de xin qixiang' (New Atmosphere in Shanghai's Traditional Theatre Performance), Xiju bao (Theatre Gazette), 11 (1956), p. 38. 
14 For a detailed analysis of this process see Liu, Performing Hybridity in Colonial-Modern China, pp. 106-14.

15 For a detailed discussion of the production see ibid., pp. 44-50.

16 Feng Guanghan, 'Daodao didi de Shanghai bendi juzhong - tongsu huaju huajixi guanmo yanchu' (Purely Local Shanghai Theatrical Genres - Popular Spoken Drama and Farcical Drama Observational Performance), Jiefang ribao (Liberation Daily), 9 January 1957, p. 2; Xinhua New Agency, 'Shanghai juxing tongsu huaju guanmo huiyan' (Popular Spoken Drama Observational Performance Festival Held in Shanghai), Renmin ribao (People's Daily), 11 January 1957, p. 7.

17 Anonymous, 'Juyou xianming tese de tongsu huaju' (Popular Spoken Drama with a Distinctive Style), Xiju bao (Theatre Gazette), 12 (1957), p. 12.

18 See He Man, 'Fuyou minzu yishu tese de xiju - tan tongsu huaju "Zhenzhu ta"' (A Play Full of National Artistic Colors - On the Popular Spoken Drama Pearl Pagoda), Jiefang ribao (Liberation Daily), 20 January 1957, p. 4; Chen, 'Kan Shanghai tongsu huaju huiyan'; Ma Qian, 'Tan tongsu huaju de chuantong' (On the Tradition of Popular Spoken Drama), Wenyi yuebao (Literature and Arts Monthly), 2 (1957), pp. 56-7; Zhao Mingyi, 'Tongsu huaju de laili jiqi yishu tedian' (The Origin and Artistic Characteristics of Popular Spoken Drama), Wenyi bao (Literature and Arts Gazette), 11 (1957), pp. 12-13; Ma Yanxiang, 'Tongsu huaju he huaju' (Popular Spoken Drama and Spoken Drama), Renmin ribao (People's Daily), 28 June 1957, p. 8. Ma Qian is most likely the pen name of Qian Yingyu, a Shanghai theatre official, theatre critic, playwright and director.

19 Zhongyuan, 'Tongsu huaju lao yiren huanju yitang bashi laoweng zai wutai shang shenshou jiaojie fang 'Zhenzhu ta' zhong shiyan Chen Lian de Chen Wuwo' (Old Artists of Popular Spoken Drama Gathered; Eighty-Year-Old Man Still Agile Onstage - An Interview with Chen Wuwo, Chen Lian's Performer in Pearl Pagoda), Xinmin wanbao (Xinmin Evening News), 10 January 1957, p. 2. The Anti-rightist Movement started in July 1957 after a period of liberal policies in 1956 and early 1957 that encouraged criticism of governmental bureaucracy. The movement purged roughly half a million alleged 'rightists', including those from the literary and arts circles. $\mathrm{Ma}$, 'Tongsu huaju he huaju'; Mao Zedong, 'On the Correct Handling of Contradictions among the People', at www.marxists.org/reference/archive/mao/selected-works/volume-5/mswv5_58.htm\#v5_96 Ma, 'Tan tongsu huaju de chuantong', p. 56.

Zhao Mingyi, 'Tan huaju xuexi yichan wenti' (On the Question of Spoken Drama Learning from Heritage), Wenyi yuebao (Literature and Arts Monthly), 2 (1957), p. 53. For more on wenmingxis debate over traditional versus Western structure see Chapter 4 of Liu, Performing Hybridity in Colonial-Modern China. Ma, 'Tan tongsu huaju de chuantong', p. 57.

Zhao, 'Tongsu huaju de laili jiqi yishu tedian', p. 13. Xinju was another name for wenmingxi. Zhao, 'Tan huaju xuexi yichan wenti', p. 54.

He, 'Fuyou minzu yishu tese de xiju - tan tongsu huaju "Zhenzhu ta”, p. 4.

Shanghaishi chuantong jumu bianji weiyuanhui, ed., Chuantong jumu huibian, tongsu huaju (Collection of Traditional Plays, Popular Spoken Drama), Vol. I (Shanghai: Shanghai wenyi chubanshe, 1959), p. 10.

29 Hongniang is adapted from the famous play Xixiang ji (The Story of the Western Wing) by the Yuan Dynasty playwright Wang Shifu (1250-1337?), about the romance between the scholar Zhang Sheng and Cui Yingying, daughter of a chief minister. Hongniang is Cui's maid. Chen, 'Kan Shanghai tongsu huaju huiyan'.

31 Ma, 'Tongsu huaju he huaju'.

32 Xu Zhuodai, 'Mantan tongsu huaju' (On Popular Spoken Drama), Juben (Play Script), 8 (1957), pp. 57-8. Xu Zhuodai and Xu Banmei were different names of the same person.

$33 \mathrm{Xu}$, Huaju chuangshiqi huiyilu, 60-4.

34 Huang Wenhu, 'Guanyu tigangxi' (On Outline Plays), Xiju bao (Theatre Gazette), 3 (1957), p. 27. 
For a detailed discussion of scenarios versus scripts in wenmingxi see Chapter 4 of Liu, Performing Hybridity in Colonial-Modern China.

Ouyang Yuqian, 'Huiyi Chunliu' (Recollections of the Spring Willow Society), Xiju luncong (Theatre Forum), 3 (1957), pp. 43-68; Ouyang, 'Tan Mubiaoxi' (On Scenario Plays), Xiju luncong (Theatre Forum), 4 (1957), pp. 104-9; Ouyang, 'Huiyi Chunliu', in Tian Han et al., eds., Zhongguo huaju yundong wushi nian shiliao ji (Collected Resources of Fifty Years of Chinese Spoken Drama), Vol. I (Beijing: Zhongguo xiju chubanshe, 1985), pp. 13-46; Ouyang, 'Tan wenmingxi' (On Civilized Drama), in ibid., pp. 47-106.

37 See Liu, Performing Hybridity in Colonial-Modern China, pp. 97-107.

38 Ouyang, 'Tan Mubiaoxi', p. 107.

39 Ibid., pp. 106-9.

$40 \quad$ Li Hong, 'Di si zhong juben' (The Fourth Type of Play). Nanjing ribao (Nanjing Daily), 11 June 1957.

41 Ouyang, 'Tan wenmingxi', p. 77.

42 For a historical account of this narrative see Liu, Performing Hybridity in Colonial-Modern China, pp. 7-10.

43 Shanghaishi chuantong jumu bianji weiyuanhui, ed., Chuantong jumu huibian, tongsu huaju (Collection of Traditional Plays, Popular Spoken Drama), 7 vols. (Shanghai: Shanghai wenyi chubanshe, 1959-62).

44 Liu Ying, 'Wanqi wenmingxi: gailiang yu yanbian' (Late Period Civilized Drama: Reform and Evolution), MA thesis (Shanghai Theatre Academy, 2002), pp. 18-19.

45 Wu Saiwen, Sange muqin (Three Mothers) (Shanghai: Shanghai wenyi chubanshe, 1959), p. 69.

46 Yao Shixiao, 'Ping tongsu huaju Sange muqin' (On Popular Spoken Drama Three Mothers), Xiju bao (Theatre Gazette), 7 (1959), p. 7.

47 Ibid.

48 Kuang Xilu, 'Shanghai xiju jie de xishi: Zhaoyang, Mifeng liang jutuan huaru Renyi jianzhi; Shanghai Shi mu'ou, piying jutuan chengli' (Happy Events for Shanghai Theatre World: Zhaoyang and Mifeng Companies Merged into Shanghai People's Art Theatre; Puppet and Shadow Puppet Company Established), Shanghai xiju (Shanghai Theatre), 6 (1960), p. 28; Lin, 'Fanying da shidai gechang gongnongbing: benshi juxing 1960 nian xiandai ticai jumu guanmo yanchu' (Reflecting the Great Era, Singing about Workers, Peasants and Soldiers: City Held 1960 Modern-Themed Plays Observational Performance), Shanghai xiju (Shanghai Theatre), 7 (1960), p. 17.

49 Chen, 'Kan Shanghai tongsu huaju huiyan'.

50 Richard Bauman and Charles L. Briggs, Voices of Modernity: Language Ideologies and the Politics of Inequality (Cambridge and New York: Cambridge University Press, 2003), pp. 195-6.

51 Shanghaishi fangyan huaju tuan, 'Fangyan huaju chuantong jumu zhengli yanchu' (Revised Traditional Dialect Spoken Drama Plays Performance Programme) 1960-66; Liu, 'Wanqi wenmingxi: gailiang yu yanbian', pp. 21-2. The four unstaged plays were Jin Xiaoyu (adapted from the wenmingxi play Rexie (Hot Blood), based on Tosca), Henhai (Sea of Regret), Qiu Jin, and Jia (The Family). Among them, Sea of Regret underwent rehearsal but did not see the stage.

52 Frank Hoff, 'Suzuki Tadashi Directs “The Trojan Women”', Theater 11, 3 (1980), pp. 43-48, here p. 43.

53 Ibid.

54 James R. Brandon, Theatre in Southeast Asia (Cambridge, MA: Harvard University Press, 1967), p. 39.

SIYUAN LIU (Siyuan.Liu@ubc.ca) is an associate professor of theatre at the University of British Columbia and editor of Asian Theatre Journal. His published books include The Routledge Handbook of Asian Theatre (2016), Performing Hybridity in Colonial-Modern China (2013), Modern Asian Theatre and Performance 1900-2000 (co-author, 2014), and The Methuen Drama Anthology of Modern Asian Plays (co-editor, 2014). 